\title{
Association between Pressure Pain Sensitivity, Performance stability and Overall Performance in Olympic Sailors
}

Ballegaard, Søren; Petersen, Pernille Bjørn; Harboe, Gitte Sommer; Gyntelberg, Finn; Faber, Jens

Published in:

Journal of Sports Medicine \& Doping Studies

DOI:

10.4172/2161-0673.1000177

Publication date:

2016

Document version

Publisher's PDF, also known as Version of record

Document license:

CC BY

Citation for published version (APA):

Ballegaard, S., Petersen, P. B., Harboe, G. S., Gyntelberg, F., \& Faber, J. (2016). Association between Pressure Pain Sensitivity, Performance stability and Overall Performance in Olympic Sailors. Journal of Sports Medicine \& Doping Studies, 2016(6), [177]. https://doi.org/10.4172/2161-0673.1000177 


\title{
Association between Pressure Pain Sensitivity, Performance stability and Overall Performance in Olympic Sailors
}

\author{
Soeren Ballegaard ${ }^{1 *}$, Pernille Bjorn Petersen ${ }^{2}$, Gitte Sommer Harboe ${ }^{2}$, Finn Gyntelberg ${ }^{3}$ and Jens Faber ${ }^{1}$ \\ ${ }^{1}$ Department of Medicine O, Endocrine Unit, Copenhagen University, Denmark \\ 2UII Care, 2900 Hellerup, Denmark \\ ${ }^{3}$ The National Research Center for the Working Environment, Denmark
}

\begin{abstract}
Background: During sports competitions, the performance of athletes may be negatively affected by persistent stress and autonomic nervous system (ANS) dysfunction, both of which can be assessed by pressure pain sensitivity (PPS) at the chest bone.

Objectives: To test the association between PPS and sports performance; does a reduction of an elevated PPS improve performance stability and overall performance in Olympic sailors?

Methods: The case study included two male athletes during eight months of observation prior to and during Olympic sailing. The daily PPS self-measurements served as feedback guide for persistent stress and ANS dysfunction. Performance stability, overall performance and PPS measure were assessed at three intervals.

Results: At baseline, the median PPS was 81, the performance stability was inferior to the mean top 10 competitors, and the overall performance was rank eight. During the observation period, PPS, performance stability and overall performance improved incrementally and significantly. This eventually led the sailors to achieve an Olympic Gold. The PPS, performance stability, and overall performance were all internally closely associated (correlation coefficients: $r>$ $0.70 ; p<0.001)$.
\end{abstract}

Conclusion: The study may suggest a link between persistent stress and ANS dysfunction as assessed by PPS on one side and performance stability and overall performance on the other side.

Keywords: Autonomic nervous system dysfunction; Pressure pain sensitivity; Sports performance; Stress; Stress resilience; Persistent stress; Transient stress

\section{Introduction}

In sports, stress can either be pleasant or unpleasant and can improve or deteriorate the performance of athletes depending on the individual's balance between perceptions and expectations of the challenge and the resources available. Thus, it is essential to distinguish between transient and persistent stress. Transient stress is the physiological state of preparedness, which is automatically induced in the body through neural/hormonal signals from the brain when the athlete perceives or anticipates a challenge. It increases the performance through a broad range of physiological changes. When the challenge is over, homeostasis is re-established [1,2]. In contrast, persistent stress represents prolonged exposure to the same processes as in transient stress but may be regarded as a dysfunction of the brain exemplified by function of the autonomic nervous system (ANS). [3]. Persistent stress is likely to have a negative effect on all the performance-enhancing qualities of transient stress [4,5] and may therefore deteriorate performance [6].

For athletes, participation in the Olympic Games is the highest achievement; this is inevitably linked to a large burden of stress both long before and during the competition [7]. In sailing, a prerequisite to success is the ability to multitask as the wind, current, and wave conditions change constantly. This makes sailing an unpredictable sport that is often associated with fluctuating results. Accordingly, the maintenance of a low level of persistent stress during the entire competition period is essential for a stable performance and a thus good result [8].

The measurement of pressure pain sensitivity (PPS) of the chest bone has been found to be a reliable measure for transient and persistent stress [9-12]. It seems to be associated with ANS dysfunction [3] and is feasible for home measurement with high precision $[3,13,14]$. In transient stress, short-term fluctuations in PPS are observed in parallel with concomitant changes in heart rate and blood pressure (BP) $[3,9]$. In persistent stress, resting PPS has been found to be elevated and is associated with i) elevated resting heart rate and elevated resting work of the heart assessed as Pressure-Rate-Product [9], ii) reduced physical and mental quality of life evaluated from questionnaires [10-12], iii) as well as with signs of dysfunction of the ANS, as assessed as a blunted PPS, BP and heart rate response to transient gravity stress induced experimentally by a tilt table test [3]. A PPS guided stress management program, including acupressure, has been found to reduce elevated PPS. It has concomitant and clinically relevant effects on the peak performance-related variables, such as heart rate, BP and work of the heart [13], psychological well-being [12,14] and ANS dysfunction [3]. During the last three months prior to the Olympic games, this medical stress management program was included as an additional feature to a comprehensive training, stress management and resource allocating program developed by the sailors' coach. The program of the coach has been successful previously with respect to overall performance, including two personal Olympic Gold medals in sailing by the coach.

The present case report describes the association between PPS and

*Corresponding author: Soeren Ballegaard MD, Senior Scientist, Department of Endocrinology, Herlev University Hospital, 2730 Herlev, Denmark, Tel: +45 40192645; E-mail: sba@ullcare.com

Received November 28, 2015; Accepted March 28, 2016; Published April 05 2016

Citation: Ballegaard S, Petersen PB, Harboe GS, Gyntelberg F, Faber J (2016) Association between Pressure Pain Sensitivity, Performance stability and Overall Performance in Olympic Sailors. J Sports Med Doping Stud 6: 177. doi:10.4172/2161-0673.1000177

Copyright: (c) 2016 Ballegaard S, et al. This is an open-access article distributed under the terms of the Creative Commons Attribution License, which permits unrestricted use, distribution, and reproduction in any medium, provided the original author and source are credited. 
the performance of the two sailors during the period of preparation as well as participation in an Olympic regatta. The idea was based on clinical observations among former Olympic participants (personal communications). As such, this case study served as the hypothesis forming study for a subsequent study in 361 patients with stable ischemic heart disease, who underwent a fully controlled physiological experiment with the aim to test the possible association between PPS, persistent stress and ANS dysfunction [3]. Since the study found a strong association between PPS and ANS dysfunction [3], the publication of the present case report may become appropriate.

\section{Methods and Material}

\section{Participants}

Two healthy male athletes, aged 26 and 29 years, were studied during the last three months prior to and during the 2008 Olympic Games in Beijing, where they represented Denmark in the 49'er boat class. When nominated for participation, the team had achieved only rank 6 in an international regatta during the past four years. At baseline, the resting systolic BP of both the athletes (118/114 $\mathrm{mm} \mathrm{Hg}$, respectively), heart rate: $51 / 43$ beats per min, and body mass index: $21.5 / 20.8 \mathrm{~kg} / \mathrm{m}^{2}$. With respect to the SF 36 questionnaire: the Mental Component Summary score: $57 / 52$ (the lower $25 \%$ and $50 \%$ percentiles in general Danish population matched for gender and age: 52 and 57, respectively); Physical Component Summary score: 59/56 (the lower 25\% and 50\% percentiles in general Danish population matched for gender and age: 53 and 56 respectively); Clinical Stress Score [15]: 10/40 (e.g. in patients with stable ischemic heart disease, a score $\geq 40$ was found the be associated with reduced health) [11]; personal perception of stress level: $3 / 3$ on a 7 -point ordinal scale $(0=$ no stress, $6=$ maximum stress); and personal perception of average level of stress during the past three months: $2 / 4$ on the same 7 -point ordinal scale.

\section{Study design and flow of the study}

The study was a three-step prospective open case-intervention feasibility field study with no control group. Step one: Baseline PPS measurement of the level of persistent stress three months prior to the Olympic Games. A resting PPS measure $\geq 60$ (PPS units) was used as an indicator of an elevated stress level $[3,10,13,14]$. Step two: One month of additional medical stress management intervention with the aim to reduce PPS. Step three: Two months of additional medical stress management intervention with the aim to reduce PPS further.

\section{Effect variables}

PPS measure: The PPS of the sternum was recorded using an instrument (Ull Meter ${ }^{\circledR}$ ), which has been reported to be reliable and highly precise measure for transient and persistent stress [9-12] as well as for ANS dysfunction [3]. The instrument transforms pressure pain threshold mathematically into a logarithmic scale of sensitivity level (from 0 to 99 PPS units). The subjects were informed not to smoke tobacco, drink coffee or alcohol, take medication or do heavy physical exercise two hours prior to the baseline examination. The measurements were conducted with the subject in a supine position and after $10 \mathrm{~min}$ of rest.

Each measurement started with two measurements on the control point, the dorsal part of the middle phalanx on the left index finger, during which the technique and procedure was introduced. The measuring device (Ull Meter) was applied with a gradually increase of pressure, in total allowing 3-4 seconds pressure time. The subject was instructed to say "Stop" as soon as discomfort was felt. If the researcher observed a startle or withdrawal reflex, this was considered as a stop signal as well. Subsequently, measurements on the sternum were conducted following the same procedure. The point for measuring (active point) was identified by palpation of the observer as the most tender point on the sternum within the area between the third, fourth and fifth intercostal space, reflecting the area of segmental innervations of the heart of the heart [16].

Baseline measurements were conducted on an afternoon and the subsequent morning in May 2008. During the regattas, the measurements were recorded as the first thing in the morning in order to ensure comparable measurement conditions, allowing a night of rest and recovery. The sailors were instructed to conduct home PPS measurement during the observation period prior to the Olympic Games but not during the Games.

Measurement of overall performance: The World Cup in Melbourne, Australia in January 2008 was chosen as the baseline race. The PreOlympic Regatta in Kiel, Germany in June 2008 (Kiel) and the Olympic Games in Beijing, China in August 2008 (Beijing) were the other regattas. The results from the individual regattas were obtained from the official website [15].

Measurement of performance stability: Performance stability was included as an independent effect variable and a behavioural marker for ANS dysfunction based on the following notion, which was confirmed by past Danish Olympic sailors (personal communications): "As sailing is a complex multitask oriented performance and with each competitive event contained many races in close order, the performance will be stable when transient stress is dominant. In contrast, if persistent stress is dominant, the performance will be less stable". Performance stability was evaluated by using the results for the top 10 boats in the overall standings. For each regatta, the accumulated results (race points) for all races ( 8 at Baseline, 16 in Kiel and 13 in Beijing) were calculated as mean values ( \pm standard deviation) for the top 10 boats among all participants (25 participants for World Cup and 19 for the latter two regattas) compared to the position of the Danish boat. The difference between the two curves illustrates whether the performance of the Danish boat was inferior, equal to or superior to the mean top 10 boats.

\section{Intervention}

The intervention included two parts: I) A comprehensive preparation program developed by the sailors coach, Jesper Bank, that was conducted during the entire observation period of eight months, and II) a medically developed stress management program included as a specific add-on during the last three months of the observation period.

The program of the sailors coach included the following features of general stress management: 1) Early planning such as all technical aspects were concluded months before the Olympic Regatta; 2) the sailors had a two week break just prior to the Olympic Regatta; 3) the sailors participated in the Olympic Opening Ceremony in contrast to their competitors who were exercising at that time, 4) the coach exhibited calmness, authority and confidence in critical situations and between the individual races.

The medical stress management program included the following elements: The participants were instructed to do the following tasks daily: 1) PPS measurement as a biofeedback marker for stress and to apply cognitive reflection to the measure, and 2) acupressure on four selected points in the morning and evening. They were educated about the physiological background for the link between transient and persistent stress with respect to performance ability and cognitive reflection with respect to the PPS measure. They were also provided a booklet regarding the stress management program. This concept 
has been described in detail previously [17-19]. Acupuncture was performed by health care professionals according to the traditional Chinese practice [20], acupressure (i.e. finger pressure) was applied for approximately 45 seconds, on specific points on the body surface, sufficiently hard to feel it but without causing pain. The acupressure is conducted successfully when the subject can observe a decrease of tenderness within a minute of pressure. The daily acupressure had two main purposes: (i) reestablish and maintain the adaptability of the brain through repeated stimulation of the Diffuse Noxious Inhibitory Control (DNIC) system [21], and (ii) reduce stress through nonnoxious sensory nerve stimulation mediated release of oxytocin [22]. It should be emphasised that the medical stress management program was an add-on to the comprehensive program of the sailor's coach. Furthermore, the daily PPS measurement of the sailors recorded the combined effect of the two programs in use and thus served as an overall guideline for the conducted efforts with respect to stress management.

\section{Statistics}

For statistical analysis, SPSS 13.0 was used for Windows. A nonparametric Wilcoxon signed rank test was used for comparison of the two measurement points. A Kendall non-parametric correlation test was used for analysis of the correlation between the individual effect variables. Two-sided statistics were used with a 5\% significance level.

\section{Ethics}

The study was conducted in accordance with the Danish medical regulations and the World Medical Association guidelines for good clinical practice and included written informed consents by the participants.

\section{Results}

The median baseline PPS measures for May 2008 were 81 (8 PPS measurements), whereas that measured during the Kieler Woche was 56 (7 measurements) and during the Olympic Games was 39 (11 measurements). With respect to the overall performance, the best result of the studied team at a Level A regatta in 2008 before the baseline PPS measurement (May 2008) was rank 8 (World Championships, January 2008)(25 participants; 8 races), compared to rank 3 in Kieler Woche in June 2008 (19 participants, 16 races) and rank 1 at the Olympic Games in August 2008 (19 participants, 13 races). These final positions in the three races, as a measure of performance, correlated with the PPS measure, $\mathrm{r}=0.7(\mathrm{p}<0.0001)$. Moreover, the steady decrease in PPS from May to August 2008 was statistically significant $(\mathrm{p}<0.001)$ (Figure 1).

Performance stability correlated positively to overall performance $(r=0.7 ; p<0.0001)$ and to PPS $(r=0.7 ; p<0.0001)$. Figure 2 shows the performance stability for the three races. The differences in slopes illustrate that the sailing stability of the Danish boat was inferior to the mean of the other top 10 boats for the World Cup (Figure 2a). This was similar to that of the rest of the top 10 boats for Kiel (Figure 2b) and superior during the Olympic Games (Figure 2c). The accumulated differences between the mean top 10 boat and the Danish boat were 165 arbitrary units for World Cup in which the Danish boat performed inferior in all 8 races, 0 in the Pre-Olympic race in which the Danish boat performed inferior in 10 out of 16 races, and 202 at the Olympic Games in which the Danish boat performed superior in all 13 races.

During the Olympic Games, the morning PPS measure (median 39; range 51-34) was consistently lower than the preceding evening PPS measure (median 44, range $59-41$ ), with a median reduction of -7 PPS units (range -2 to -22$)(p=0.02)$. The highest evening measure was 59,

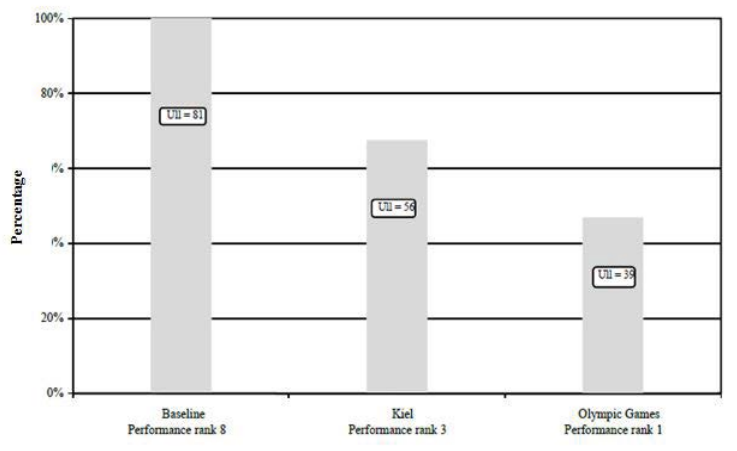

Figure 1: The relationship between PPS and overall performance at three regattas: 1) at baseline (World Cup Australia), 2) after one months of intervention for lowering PPS measures: Pre-Olympic regatta (Kiel), and 3 ) after 3 months of PPS lowering intervention: Olympic Games

and the next morning PPS measure was 38 (a 35\% reduction).

\section{Discussion}

The study demonstrates that the lower the PPS, the better the performance stability and the overall performance. The reduction of an elevated PPS, first during the one-month period from baseline to Kiel and then during the subsequent two months from Kiel to Beijing, was associated with improved overall performance.

These results are in line with previous findings that PPS seems to reflect transient as well as persistent stress. With respect to transient stress, the short-term fluctuations in PPS have previously been demonstrated [3,9]. With respect to persistent stress, an elevated PPS has been found to be associated with a reduced PPS response to transient stress [3]. Moreover, when an elevated resting PPS, as an indication of an increased level of persistent stress, was reduced during the active intervention, the resting $\mathrm{BP}$, heart rate and work of the heart were found to be reduced [13]. In addition, the ANS dysfunction was reversed, and the PPS response to an experimental transient physiological stress situation was increased [3]. In the present study, we found that a low PPS at the end of the intervention period was associated with the peak performance and daily fluctuations in PPS (median over-night reduction: -7 PPS units), which were larger than those for 42 office workers with persistent stress during three months of observation (median reduction: -2 PPS units) [10]. The apparently larger daily PPS fluctuations in the athletes during the Olympic Games, when compared to the stressed office workers, may indicate an improvement in their recovery and adaptive capacity during the intervention period [4].

A resting PPS $\geq 60$ has been used as a discrimination point for an elevated level of persistent stress and as an indicator of ANS dysfunction in patients with stable ischemic heart disease. Among these patients, the mean change in PPS during tilt table test was + 1 PPS unit for 155 patients with a resting PPS $<60$ compared to -7 PPS units for the 206 patients with a PPS $\geq 60$. The latter negative response is an indication of ANS dysfunction [3]. For those patients, who during the threemonths intervention period experienced a reduction in resting PPS of $\geq 15$ units, the mean PPS response to a tilt table test increased + 12 PPS units when compared to the baseline response. These findings suggest that persistent stress, measured as an elevated resting PPS, is associated with the reduction of the PPS response to sleep and experimentallyinduced transient stress. Thus, resting PPS serves as an indication of ANS dysfunction. Moreover, when an elevated PPS is reduced, the 
Summary Points

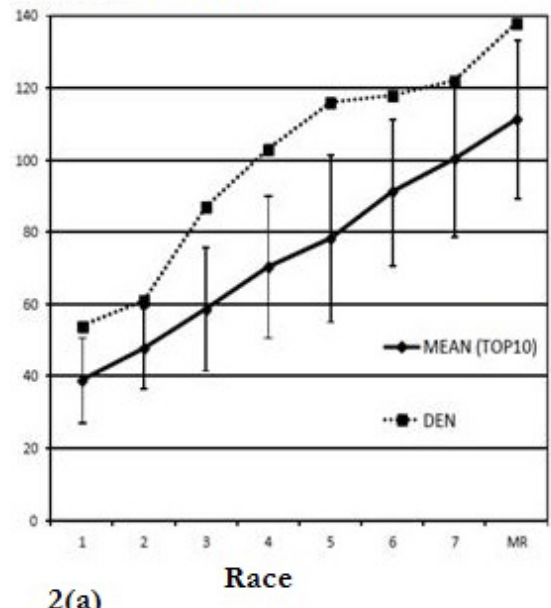

Summary Points

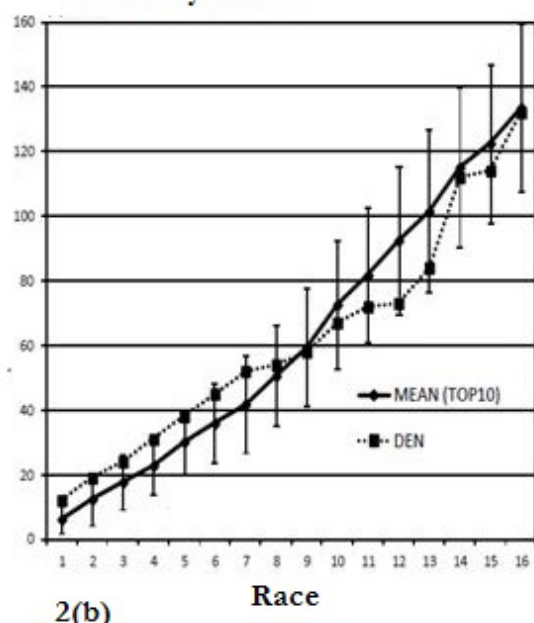

Summary Points

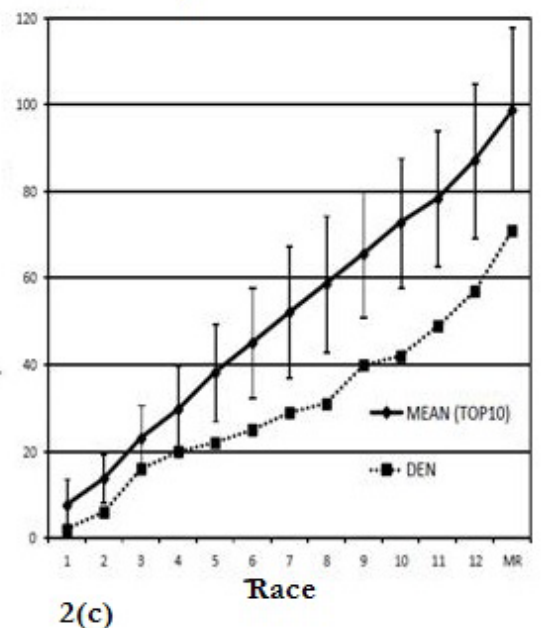

Figure 2: (a)Baseline World Cup, Australia, January 2008; (b) Kiel Regatta, Germany, June 2008; (c) Olympic Games, Beijing, China, August 2008 .

PPS response to sleep and experimentally-induced transient stress increases, indicating a restoration of ANS dysfunction. Among the Olympic sailors of this case study, the PPs was reduced from 81 to 39 which may represent an explanation for improved ANS function, improved performance stability and overall performance.

Accordingly, the results may indicate an association between PPS, ANS dysfunction, and recovery capacity on one side and performance stability and overall performance on the other side.

In the high-performance Judo sport, the baseline ANS dysfunction has been found to influence physical performance [23]. An attenuated ANS modulation response with respect to orthostatic and cognitive tests has been observed in over-trained athletes [24]. The present findings are in line with these studies, suggesting an association between ANS dysfunction and reduced peak performance.

The purpose of the total intervention program was to ensure optimal balance between resources and strain on the athletes during the preparation period in order to build up towards a peak performance at the Olympic Games. As the resting PPS in May 2008 was elevated and the team of sailors made a non-peak performance (overall position: No. 6) at a level B-regatta in May 2008, the elevated resting PPS served as one possible physiological performance-related factor, which could potentially be improved.

The medical stress management intervention used as an add-on in this study had a dual purpose. Firstly, to provide ongoing (i.e. daily) information to the athletes and the support team if their level of stress was elevated in order to allow appropriate cognitive reflection and action with respect to the conduction of the comprehensive training and stress management program of the coach. As an example, this purpose was met by a situation in which professional assistance became in demand, as one of the participants during the preparation period less than one month prior to the Olympic Regatta measured an elevated PPS (> 75 PPS units) in a situation with unexpected environmental psychological strain. The second purpose was to provide an add-on to the stress management program of the coach that was already in use. The mutual aim of the combined programs was to lower an elevated PPS and ensure a consistently low PPS during the Olympics.

This case report cannot be hypothesis testing as only one boat and two sailors are included with no randomised control group. Other limitations of this report include the four-month time delay between the baseline overall performance (World Cup January 2008) and the baseline PPS measure. However, the endpoints were few, and a high number of consecutive PPS measurements were conducted during the last three-month period prior to the Olympic Games.

In conclusion, the findings of this study suggests that the PPS reflects persistent stress and ANS dysfunction and is applicable to improve performance in athletes.

\section{Acknowledgement}

The authors are grateful to the coach of the sailors, Jesper Bank, and to Professor MD DMSci Niels H. Secher, Department of Anesthesiology, Rigshospitalet, Denmark, for crtical review of the manuscript. We thank Benny Karpatschof, Department of Psychology, Copenhagen University for statistical analysis.

\section{Author Disclosure Statement}

This study received financial support from UII Care A/S, in which Soeren Ballegaard is a shareholder. Soeren Ballegaard is also a shareholder in UII Meter $\mathrm{A} / \mathrm{S}$, who holds the patent for the instrument used in this study. No other authors have any conflict of interest to disclose.

\section{References}

1. McEwen BS (1998) Stress, adaptation, and disease. Allostasis and allostatic load. Ann N Y Acad Sci 840: 33-44.

2. Korte SM, Koolhaas JM, Wingfield JC, McEwen BS (2005) The Darwinian concept of stress: benefits of allostasis and costs of allostatic load and the trade-offs in health and disease. Neurosci Biobehav Rev 29: 3-38.

3. Ballegaard S, Bergmann N, Karpatschof B, Kristiansen J, Gyntelberg F, et al (2015) Association between pressure pain sensitivity and autonomic function as assessed by a tilt table test. Scand J Clin Lab Invest 75: 345-354.

4. McEwen BS (2005) Stressed or stressed out: what is the difference? J Psychiatry Neurosci 30: 315-318.

5. Kumazawa T (1998) Primitivism and plasticity of pain--implication of polymodal receptors. Neurosci Res 32: 9-31.

6. Kellmann M, Günther KD (2000) Changes in stress and recovery in elite rowers during preparation for the Olympic Games. Med Sci Sports Exerc 32: 676-683.

7. Kristiansen E, Roberts GC (2010) Young elite athletes and social support: coping with competitive and organizational stress in "Olympic" competition Scand J Med Sci Sports 20: 686-695.

8. Durand-Bush N, Salmela JH (2002) The Development and Maintenance of 
Citation: Ballegaard S, Petersen PB, Harboe GS, Gyntelberg F, Faber J (2016) Association between Pressure Pain Sensitivity, Performance stability and Overall Performance in Olympic Sailors. J Sports Med Doping Stud 6: 177. doi:10.4172/2161-0673.1000177

Page 5 of 5

Expert Athletic Performance: Perceptions of World and Olympic Champions. Journal of Applied Sports Psychology 14: 154-171.

9. Ballegaard S, Karpatschof B, Trojaborg W, Hansen AM, Magnusson G, et al. (2009) A simple and objective marker for stress. Scand J Clin Lab Invest 69 : 713-721.

10. Ballegaard S, Petersen PB, Gyntelberg F, Faber J (2012) The association between pressure pain sensitivity, and answers to questionnaires estimating psychological stress level in the workplace. A feasibility study. Scand J Clin Lab Invest 72: 459-466.

11. Bergmann N, Ballegaard S, Holmager P, Kristiansen J, Gyntelberg F, et al. (2013) Pressure pain sensitivity: a new method of stress measurement in patients with ischemic heart disease. Scand J Clin Lab Invest 73: 373-379.

12. Axelsson CK, Ballegaard S, Karpatschof B, Schousen P (2014) Pressure pain sensitivity as a marker for stress and pressure pain sensitivity-guided stress management in women with primary breast cancer. Scand J Clin Lab Invest 74: 399-407.

13. Ballegaard S, Petersen PB, Harboe GS, Karpatschof B, Gyntelberg F, Faber $J$ (2014) The association between changes in pressure pain sensitivity and changes in cardiovascular physiological factors associated with persistent stress. Scand J Clin Lab Invest 74: 116-125

14. Bergmann N, Ballegaard S, Bech P, Hjalmarson A, Krogh J, et al. (2014) The effect of daily self-measurement of pressure pain sensitivity followed by acupressure on depression and quality of life versus treatment as usual in ischemic heart disease: a randomized clinical trial. PLOS ONE 9: e97553.

15. Ballegard Clinical Stress Score official website

16. Williams PL, Bannister LH, Berry MM, Collins P, Dyson M (1995) The anatomical basis of Medicine and Surgery. In: Ferguson MWJ (ed.). Gray's Anatomy. (38thedtn). New York: Churchill Livingstone, pp: 538-546.

17. Ballegaard S, Johannessen A, Karpatschof B, Nyboe J (1999) Addition of acupuncture and self-care education in the treatment of patients with severe angina pectoris may be cost beneficial: an open, prospective study. J Altern Complement Med 5: 405-413.

18. Magnusson G, Ballegaard S, Karpatschof B, Nyboe J (2010) Long-term effects of integrated rehabilitation in patients with stroke: a nonrandomized comparative feasibility study. J Altern Complement Med 16: 369-374.

19. Ballegaard S, Borg E, Karpatschof B, Nyboe J, Johannessen A (2004) Long term effects of integrated rehabilitation in patients with advanced angina pectoris: a nonrandomized comparative study. J Altern Complement Med 10 777-783.

20. OConner J, Bensky D (1981) Shanghai College of Traditional Medicine: Acupuncture a comprehensive text. Seattle: Eastland Press.

21. Arendt-Nielsen L, Yarnitsky D (2009) Experimental and clinical applications of quantitative sensory testing applied to skin, muscles and viscera. J Pain 10 556-572.

22. Uvnäs-Moberg K (1997) Oxytocin linked antistress effects--the relaxation and growth response. Acta Physiol Scand Suppl 640: 38-42.

23. Blasco-Lafarga C, Martinez-Navarro I, Mateo-March M (2013) Is baseline cardiac autonomic modulation related to performance and physiological responses following a supramaximal Judo test? PLoS One 8: e78584.

24. Hynynen E, Uusitalo A, Konttinen N, Rusko H (2008) Cardiac autonomic responses to standing up and cognitive task in overtrained athletes. Int J Sports Med 29: 552-558.
Citation: Ballegaard S, Petersen PB, Harboe GS, Gyntelberg F, Faber J (2016) Association between Pressure Pain Sensitivity, Performance stability and Overall Performance in Olympic Sailors. J Sports Med Doping Stud 6: 177. doi:10.4172/2161-0673.1000177

\section{OMICS International: Publication Benefits \& Features}

\section{Unique features:}

- Increased global visibility of articles through worldwide distribution and indexing

- Showcasing recent research output in a timely and updated manner

- Special issues on the current trends of scientific research

Special features:

- 700 Open Access Journals

50,000 editorial team

Rapid review proces

Quality and quick editorial, review and publication processing

Indexing at PubMed (partial), Scopus, DOAJ, EBSCO, Index Copernicus and Google Scholar etc

Sharing Option: Social Networking Enabled

Authors, Reviewers and Editors rewarded with online Scientific Credits

Better discount for your subsequent articles

Submit your manuscript at: http://www.omicsgroup.org/submission/ 